DOI 10.5216/ia.v46i3.70669

\title{
PEDAGOGIAS NEGRAS: O ANTIRRACISMO, O BEM VIVER E A CORPOREIDADE
}

\author{
EDILZA CoRREIA SOtero \\ Universidade Federal da Bahia (UFBA), Salvador, Bahia, Brasil \\ ILAINA DAMASCENO PEREIRA \\ Universidade do Estado do Rio de Janeiro (UERJ), Rio de Janeiro, Brasil \\ SÔNIA BEATRIZ DOS SANTOS \\ Universidade do Estado do Rio de Janeiro (UERJ), Rio de Janeiro, Brasil
}

\begin{abstract}
Resumo: As pedagogias negras compreendem modos de fazer, pensar e ser capazes de transformar e questionar conhecimentos e práticas já estabelecidos nas pedagogias ocidentais. Também problematizam as próprias propostas gestadas no âmbito das práticas negras de ensinar e aprender. Num esforço de compreensão, discutimos antirracismo, pensamento de mulheres negras e corporeidades à luz de três estratégias metodológicas - multiplicidade, complexidade e interdependência, revelando compressões sobre os processos de aprender-ensinar-criar que configuram as pedagogias negras. Por fim, consideramos que essas pedagogias mobilizam a luta pelos direitos em suas várias dimensões, em especial o direito à diferença, enquanto direito fundamental e inalienável.
\end{abstract}

Palavras-chave: Pedagogias Negras. Antirracismo. Mulheres Negras. Corporeidade.

INTRODUÇÃO

As pedagogias negras são processos amplos de busca por novos modos de aprender, conhecer e ser, intrinsecamente relacionados com a luta por direitos. O direito à educação, o direito à justiça e segurança e o direito à diferença se colocam aqui como elementos que despontam nas narrativas das autoras deste artigo. Mas há muitas outras propostas invisibilizadas que devem ser consideradas dentro de um quadro amplo e complexo dos modos de organização e reivindicação que acessamos quando buscamos informações sobre as formas pelas quais as populações negras aprendem e compartilham conhecimentos.

Refletir sobre o que seriam pedagogias negras nos impõe o desafio de considerar a multiplicidade, a complexidade e a interdependência das experiências vividas por pessoas negras na diáspora. A multiplicidade considera os contextos nos quais a vida desses sujeitos se realizou e materializou, bem como os modos diversos de criar estratégias de sobrevivência e construção de modos de vida nos quais pudessem construir seus laços de comunidade e reconstruir sua humanidade. A complexidade aponta para a importância de olhares treinados para compreender as estratégias de aprendizagem e compartilhamento de conhecimentos das populações negras. A interdependência nos propõe analisar as relações implícitas que cada estratégia destes grupos negros tem para acessar educação, compartilhar saberes e conhecimentos e criar e usar de meios e mensagens para divulgar suas reivindicações e ações.

Inter-Ação, Goiânia, v.46, n.3, p. 1314-1329, set./dez. 2021. Disponível em: <http://dx.doi.org/10.5216/ia.v46i3.70669>. 
A multiplicidade, num primeiro momento, se apresenta como resultado das pesquisas que realizamos com vistas a encontrar debates, pesquisas e reflexões sobre o tema "Pedagogias Negras". Em uma breve pesquisa nas bases de dados do Google Acadêmico, Scielo e Banco de teses e dissertações da Capes, compreendendo todo o período disponível para consulta em cada um desses repositórios, encontramos apenas uma citação direta ao termo, referindo-se ao conjunto da obra de bell hooks. Além desta referência, localizamos diversas expressões, das quais destacamos algumas: “Pedagogia das mulheres em movimento, Pedagogia do movimento de mulheres negras, Pedagogia Negra Feminista, Pedagogia dos terreiros, Pedagogias da imprensa negra, Pedagogia de coletivos negros, Pedagogia dos intelectuais negros, Pedagogias antirracistas, Negros processos pedagógicos e Pedagogias descoloniais". Cada uma dessas sentenças traz a multiplicidade dos saberes-fazeres-aprendizagens negras como marca fundamental, pois as pedagogias não se restringem à educação formal, elas abarcam processos amplos de reconhecimento, luta e conquistas sociais concebidas em diferentes setores da vida.

A multiplicidade ilumina as frentes de luta, as pautas de reivindicação, os locais e os contextos históricos, afirmando toda a criatividade e capacidade adaptativa dos sujeitos negros mobilizados. Reconhecer esses modos de pensar, as ações e os modos pelos quais somos educados, nessas atividades e nesses meios, nos possibilita compreender a necessidade das populações negras de adaptar seus modos de agir para a conquista de melhores condições de vida, que implica a construção de práticas e conteúdos adequados e que atendam às necessidades das populações negras.

Cada uma das expressões descritas traz também a complexidade de organizar modos de aprender-ensinar-criar ao apontar contextos diversos de criação e a atenção a modos de agir e/ou pautas de reivindicações plurais. As populações negras criam estratégias para conquistar direitos diversos que passam pela comunicação; reconhecimento do pensamento intelectual negro africano e afrodiaspórico; construção de práticas de ensino mais igualitárias no currículo escolar; modos de saber e aprender na comunhão de mulheres negras em busca de um objetivo comum, incluindo saúde educação, justiça e segurança; compartilhamento do feminismo negro e outras vertentes do pensamento e ação política das mulheres negras, como campo de aprendizagem social, e as organizações de jovens, cujas pautas são tão amplas quanto os modos de ser jovem e viver a juventude.

A interdependência das pedagogias negras está nas aprendizagens diversas que os sujeitos fazem uns com os outros, em seus movimentos e ações para conquista e garantia de direitos. A interdependência pressupõe reciprocidade nas pautas de reivindicação, projetos de mudança e novas maneiras de fazer nos processos de formação humana que dialogam entre si ao buscarem direitos e condições de vida dignos para as populações negras. Podemos, com isso, afirmar que há inúmeras pedagogias negras sendo, simultaneamente, vividas, gestadas e sonhadas, cotidianamente.

As pedagogias negras tratam de experiências formativas nas quais aprenderensinar-criar não são apenas partes de um processo circular infinito e ininterrupto. Elas são o conhecer, o executar e o sentir vivido pelos sujeitos e grupos sociais negros, são 
SOTERO, E. C.; PEREIRA, I. D.; SANTOS, S. B. dos.

experiências que formam pensamentos e ações estimulando a busca de práticas humanizantes, dos sujeitos em suas diferenças, e humanizadas, para reconhecer os outros em sua diversidade.

Para discutir sobre pedagogias negras com a robustez que o tema exige, destacamos a necessidade de estruturar nossa discussão em três eixos: 1) a construção do antirracismo, como a busca por condições materiais de desinvestimento no racismo estrutural; 2) a interpretação dos conceitos de Bem Viver e Amefricanidade, pelo pensamento de mulheres negras do Brasil, n0o campo das epistemologias; e 3) a criação das corporeidades como processos educativos nos quais circulam fruição estética e participação política. Esta divisão metodológica visa ampliar o debate sobre a necessidade de olhares treinados para perceber o processo de aprender-ensinar-criar das populações negras.

\section{PedAgogias nEgRAS: A CONSTRUÇÃo do ANTIRRACISMO}

Um ponto de partida é questionar sobre o que deveria ser o elemento catalisador no qual as pedagogias negras devem (deveriam) empreender seus esforços? Em nossa perspectiva, este elemento deve ser o exercício de construção do antirracismo enquanto uma realidade objetiva e subjetiva, construindo assim as condições materiais de desinvestimento no racismo estrutural. Um movimento que permita que pessoas de distintos pertencimentos étnico-raciais sejam formadas no sentido de apreenderem e empreenderem, por meio de experiências plurais, o processo de aprender-ensinar-criar em prol de um constructo sobre como ser antirracista ou como se constituir e engajar-se num movimento, atitude, ação, discurso desfavorável ao racismo, de resistência a qualquer prática racista, de discriminação e de segregação racial, e de desnaturalização e desaceite dos privilégios que ele proporciona ao se persistir na sua crença e disseminação. Pedagogias que devem nos auxiliar a desconstruir raça como "um constructo de poder da diferença inferida ou consolidada que vive socialmente" (KENDI, 2020, p. 37).

Segundo Ibram Kendi (2020), o antirracista é "alguém que apoia uma política antirracista por meio de ações ou expressando ideias antirracistas" (p. 13); "aquele que expressa a ideia de que grupos étnicos são iguais e não precisam de desenvolvimento, e apoia políticas que reduzem a desigualdade racial" (p. 25). Como as experiências com o desenvolvimento das pedagogias negras podem nos auxiliar a conscientizar pessoas a escolherem o caminho do antirracismo, mais que isto, perceber o quanto ele é crucial para a sobrevivência dos seres humanos. Como destituir argumentos racistas, as convicções de "alguém que apoia uma política racista por meio de ações ou inações, ou expressando ideias racistas" (KENDI, 2020, p. 13)?

Vislumbrando a Década Internacional dos Afrodescendentes 2015-2024, cujo tema é "Povos afrodescendentes: reconhecimento, justiça e desenvolvimento", torna-se fundamental conferir visibilidade e legitimidade às distintas e emergentes pedagogias negras. Neste sentido, no contexto da formação universitária, e em particular da formação de professores(as) e outros profissionais que atuarão na educação - ensinos básico e superior -, é fundamental pensar, não somente as práticas formais, mas também as não formais e informais que têm orientado a Educação das Relações ÉtnicoRaciais entre docentes/pesquisadoras(es) e estudantes graduandas(os) e pós- 
graduandas(os), explorando processos de aprendizagem por meio de atividades de iniciação científica, ensino e extensão dentro e fora da universidade. Docentes num sentido mais amplo, e em cursos de formação de professores devem buscar desenvolver junto às(aos) orientandas(os) práticas educacionais e de produção de conhecimento antirracistas que abordem e exponham as questões étnico-raciais na sociedade brasileira e ainda, promover a discussão na educação de estratégias de enfrentamento dos problemas gerados pelo racismo e as iniquidades acarretadas por este.

Vale ressaltar a centralidade das mulheres negras na construção de processos de formação, baseada numa perspectiva antirracista, antipatriarcal e antiheteronormativa, em instituições universitárias e nas escolas. Estas professoras e pesquisadoras têm se destacado como lideranças, fomentado estudos (novas epistemologias) e práxis na busca por estratégias de enfrentamento das desigualdades raciais per si, e em intersecção com outras formas distintas de dominação baseadas no gênero, classe, sexualidade, dentre outras. Assim, é fundamental que suas práticas sejam reconhecidas e divulgadas entre as futuras gerações, no Brasil e em outras regiões da Diáspora Africana.

Frente a uma sociedade atravessada por assimetrias socioeconômicas, culturais e políticas - estruturantes do racismo - que produzem "mecanismos geradores de prestígio ou estigma social" (PAIXÃO, 2014, p. 2), as pedagogias negras podem ser fundamentais na formação de conteúdo e massa crítica antirracista que se contraponham a discriminação e desigualdade raciais sustentadas pela sociedade brasileira, e que se reproduz através da socialização difundida pelo sistema educacional. CEPESC e SPM (2009) ressaltam que ao

[...] se falar de preconceitos étnico-raciais no currículo escolar, [...] nos deparamos com formas explícitas de inferiorização de negros/as e de indígenas, e de supervalorização de brancos/as no currículo escolar como um todo e nos livros didáticos e paradidáticos em particular [...] (p. 243).

E ainda enfatizam que "não é possível educar para a igualdade étnico-racial" sem romper com os estigmas, com as linguagens explicitadas ou não de inferioridade de negros/as e indígenas [...] (p. 247).

Adicionalmente, Gomes e Silva (2011), salientam a importância de se garantir que os processos educativos e de formação dos indivíduos não tomem "a diferença como estigma (...)", pois ela "é mais um constituinte do nosso processo de humanização. Por meio dela, nós nos tornamos partícipes do processo da formação humana" (p. 18).

Um outro aspecto importante é que um modelo de educação antirracista precisa garantir a conscientização e enfrentamento de outras formas de preconceito e discriminação, a exemplo das opressões de gênero, homofobia e transfobia.

Um último fator importante a se considerar sobre as contribuições das pedagogias negras, na perspectiva antirracista, se refere a nos auxiliar a pensar e repensar as vivências escolares e acadêmicas de pessoas negras - estudantes, suas 
SOTERO, E. C.; PEREIRA, I. D.; SANTOS, S. B. dos.

famílias e profissionais que trabalham no ambiente educacional. Tais vivências envolvem enorme complexidade, que perpassam pela garantia de recursos financeiros que assegurem a manu- tenção de necessidades fundamentais, tais como alimentação, aquisição de material didático, acesso a aportes para a formação em ensino e pesquisa, transporte, bem como compreendem vínculos construídos com professores, técnicos, colegas de turma, grupos de estudos, oportunidades de estágio, e de promoção de experiências afetivas individuais e coletivas. Percebemos que o ambiente educacional, em instituições escolares e universitárias, tem se constituído em lugares de manutenção e produção de vulnerabilidades sociais para estudantes negros(as) e de outros grupos marginalizados, impactando de forma negativa seus processos de ensino-aprendizagem (que compreendem aprender-ensinar-criar) e, como consequência, suas oportunidades educacionais e profissionais.

As pedagogias negras têm, por um lado, denunciado a precarização da vivência estudantil da população infantil e juvenil negra e de professores(as) negros(as), consentida e estabelecida pelo sistema educacional brasileiro, em todos os níveis e modalidades, e por outro, têm demonstrado a resiliência e resistência da população negra a tal processo excludente, por meio da demanda e construção de dispositivos legais, pedagógicos e políticos, e ainda, pela produção de subsídios educacionais alternativos. E neste sentido, se constitui como exemplo, as Diretrizes Curriculares Nacionais para a Educação das Relações Étnico-Raciais e para o Ensino de História e Cultura Afro-Brasileira e Africana, CNE/CP 3/2004, aprovado em 10/3/2004, Proc. 23001000215/2002-96, que "visa a atender os propósitos expressos na Indicação CNE/CP 6/ 2002, bem como regulamentar a alteração trazida à Lei 9.394/96 de Diretrizes e Bases da Educação Nacional, pela Lei 10.639/2000, que estabelece a obrigatoriedade do ensino de História e Cultura Afro-Brasileira e Africana na Educação Básica", alterada para a Lei 11.645/2008 para inclusão do ensino de História e Cultura Indígenas na Educação Básica (p. 9).

Este parecer busca garantir "o direito à igualdade de condições de vida e de cidadania, assim como garantem igual direito às histórias e culturas" dos povos que constituem a formação da sociedade brasileira, e adicionalmente, busca assegurar o "direito de acesso às diferentes fontes da cultura nacional a todos brasileiros" (BRASIL, 2004, p. 9).

O documento é uma resposta, em particular à área da educação, no que tange contemplar as demandas dos afrodescendentes pelo estabelecimento "de políticas de ações afirmativas, isto é, de políticas de reparações, e de reconhecimento e valorização de sua história, cultura, identidade". Representa um esforço em instituir uma política curricular, fundada em dimensões históricas, sociais, antropológicas oriundas da realidade brasileira, e busca combater o racismo e as discriminações que atingem particularmente os negros". (BRASIL, 2004, p. 10). Por fim, se constitui numa proposta que promove,

a divulgação e produção de conhecimentos, a formação de atitudes, posturas e valores que eduquem cidadãos orgulhosos de seu pertencimento étnico-racial - descendentes de africanos, povos indígenas, descendentes de europeus, de asiáticos - para interagirem na construção de uma nação democrática, em que 
todos, igualmente, tenham seus direitos garantidos e sua identidade valorizada. (BRASIL, 2004, p. 10).

É preciso construir a compreensão acerca do que é racismo estrutural, e de que este não é apenas um problema de pessoas negras e de outros grupos não brancos, mas ao contrário se estende a todos indivíduos, grupos e instituições. A existência do racismo e dos preconceitos e discriminações derivados deste são parte de um 'acordo social', e, como afirma Almeida (2018, p. 38), "ele é uma decorrência da própria estrutura social, ou seja, do modo 'normal' com que se constituem as relações políticas, econômicas, jurídicas e até familiares [...] o racismo é estrutural". Assim, para o autor "comportamentos individuais e processos institucionais são derivados de uma sociedade cujo racismo é regra e não exceção" (p. 38). Por conseguinte, as respostas para seu enfrentamento devem necessariamente envolver o conjunto da sociedade, pois ele "é parte de um processo social" (p. 38).

Portanto, o cenário apresentado demanda uma formação calcada nas múltiplas experiências de aprender-ensinar-criar que possibilitem uma construção de conhecimentos, social e politicamente engajados num projeto de sociedade antirracista.

\section{Pedagogia negra: OS SENTIDOS do BeM VIVER E DE AMEFRICANIDADE}

Compreendemos que os caminhos para construção do antirracismo passam também pela produção de conhecimento pautada no resgate da memória e da história das lutas de pessoas negras. A partir do conhecimento produzido pelo movimento de mulheres negras brasileiras, práticas políticas e conceitos forjados no seio da mobilização, é possível esboçar mais elementos para compreensão das pedagogias negras.

No campo das epistemologias, o pensamento de mulheres negras do Brasil, desenvolveu sua interpretação para o conceito de bem viver, compartilhado por diferentes povos e sociedades ameríndias. Sobre a origem do conceito, Alberto Acosta explica que ele está conectado a propostas radicais de mudança social, revelando a visão de mundo de povos marginalizados pela história, compreendendo experiências e práticas de um "processo proveniente da matriz comunitária de povos que vivem em harmonia com a Natureza" (ACOSTA, 2016, p. 24).

Clélia Prestes (2018) se debruça, em sua tese de doutoramento, sobre a noção de bem viver e a forma como foi reelaborado pelo movimento de mulheres negras, integrando sua prática política, explicando que ele abrange múltiplas dimensões, conectando o pessoal, o social/coletivo, o espiritual e o ambiental.

Na história recente do movimento de mulheres negras no Brasil, o conceito de bem viver ganhou repercussão na esfera pública com o slogan "contra o racismo, a violência e pelo bem viver", da Marcha das Mulheres Negras, realizada em 2015. A marcha reuniu milhares de mulheres de diferentes gerações, formas de ativismo e organizações do país. Notamos que os sentidos de bem viver que vinham sendo forjados dentro do movimento, foram especificados no conjunto de demandas, divulgadas na carta de princípios dirigida ao Estado e à Sociedade, que cobria tópicos 
SOTERO, E. C.; PEREIRA, I. D.; SANTOS, S. B. dos.

como: direito à vida e à liberdade; promoção da igualdade racial; direitos ao trabalho; direito à terra e à cidade; justiça ambiental; direito à educação; direito à justiça; direito à cultura, informação e comunicação; e segurança pública (WERNECK; IRACl; CRUZ, 2015).

O conceito passou a compor a base da rede de ativismo intitulada "Articulação de Organizações de Mulheres Negras" (AMNB) para a proposição de um novo "pacto civilizatório", elaborado a partir da sabedoria ancestral e milenar, resultando em novas possibilidades de existência individual e da vida em sociedade. Em publicação coordenada por Jurema Werneck, Nilza Iraci, Simone Cruz, os princípios que organizam o conceito são explicados.

\begin{abstract}
Na condição de protagonistas, oferecemos ao Estado e à Sociedade brasileiros nossas experiências como forma de construirmos coletivamente uma outra dinâmica de vida e ação política, que só é possível por meio da superação do racismo, do sexismo e de todas as formas de discriminação, responsáveis pela negação da humanidade de mulheres e homens negros (Carta das mulheres negras, 2015).
\end{abstract}

Quando analisamos de uma perspectiva pedagógica, o conceito de bem viver revela correspondências com a ideia de "integridade" no processo de ensino aprendizagem, desenvolvida por bell hooks (2013). A integridade se baseia na união de mente, corpo e espírito. Neste sentido, a categoria se encontra conectada ao ser individual que não se desarticula do ser coletivo. Uma noção que permite compreender os elementos que nos formam e aquilo que nos cerca.

A Marcha de Mulheres Negras resgata e mantém a tradição do Movimento das Mulheres Negras no Brasil, que tem suas raízes no final dos anos 1980 (RIOS, 2017; RODRIGUES e PRADO, 2010). Isso não significa que as mulheres negras não estivessem organizadas antes. Entretanto, a partir daquele momento, podemos observar que a forma de organização, como aconteceu também com outros movimentos sociais, passou a ser influenciada pelo processo de abertura, que culminou no fim da ditadura militar, permitindo oportunidades políticas e novos espaços para mobilização social. Destacamos ainda, que mulheres negras participavam de várias organizações, com presença significativa no movimento feminista e no movimento negro. Naquele contexto, organizações, a exemplo do Movimento Negro Unificado, configuraram-se como espaços para que mulheres negras elaborassem perspectivas políticas sobre o combate ao racismo. No entanto, suas preocupações e demandas envolvendo questões de gênero costumavam ficar em segundo plano na agenda do movimento.

No mesmo período, as Mulheres Negras também participavam de articulações do movimento feminista no Brasil. Em 1985, ocorreu o terceiro Encontro Feminista Latino-Americano e do Caribe, em Bertioga, com a participação de ativistas brasileiras e de países, como Argentina, Estados Unidos, México, Chile, Porto Rico e outras lideranças feministas internacionais. O encontro contou com a participação de lideranças de organizações de mulheres negras, como Sueli Carneiro, representando o Coletivo de Mulheres Negras de São Paulo, Lélia Gonzalez, representante do Mulherio e Thereza Santos, representante do Conselho Estadual da Condição Feminina de São Paulo.

Observamos também que, além de lideranças de organizações de mulheres negras, o encontro também contou com a participação de mulheres negras que 
atuavam em outras organizações, como o movimento de moradores de favelas do Rio de Janeiro. Catalina González (2017) explica que a participação de mulheres negras que ocupavam diferentes posições na sociedade, ensejou um discurso centrado na superação das desigualdades, levando em consideração as distinções entre mulheres no Brasil, mas também na América Latina. Descrevendo o repertório discursivo de mulheres negras brasileiras, ao longo dos anos 1980, a autora cita três demandas principais: "1) o preconceito racial e a discriminação", 2) a integração das mulheres negras na América Latina e 3) a não assimilação do ativismo feminista negro latino-americano" (GONZALES, 2017, p. 45). Essas demandas estão na gênese do feminismo negro latino-americano.

O resgate histórico do movimento de mulheres negras no Brasil é oportuno por ilustrar que a atuação delas pela defesa do bem viver tem em seu fundamento um caráter transnacional. $\mathrm{O}$ posicionamento está pautado na compreensão da violência colonial como um traço distintivo, e que se estabeleceu na exploração e no extermínio de populações negras e indígenas nas Américas.

O caráter transnacional do movimento de mulheres negras no Brasil pode ser identificado também no trabalho de pensadoras como Lélia Gonzalez (1983, 1988a, 1988b). A autora interpreta o processo colonial e suas consequências, quando apresenta a noção de Amefricanidade como uma categoria político cultural. A intelectual e ativista explica que este termo é uma "criação nossa e de nossos antepassados no continente em que vivemos, inspirados em modelos africanos", designando uma descendência que ultrapassa arranjos coloniais de território e língua (GONZALEZ, 1988a, p. 77). Esta categoria permite pensar a América com base em um princípio de unidade, com perspectiva decolonial. Pensar em unidade nestes termos é, para Lélia, pontuar a experiência histórica comum, que revela o sistema de dominação assentado no racismo, presente no pensamento/doutrina e nas instituições das sociedades que formam o continente.

Considerando a proposta de Lélia Gonzalez, ao destacar as dimensões político e cultural de Amefricanidade, é possível considerá-la também como uma pedagogia. $\mathrm{O}$ conceito atua de forma ativa para desarticular uma pedagogia da subalternidade presente na educação escolar e de forma difusa na sociedade, assentada em "estereótipos difundidos a respeito do negro: passividade, infantilidade, incapacidade intelectual, aceitação tranquila da escravidão etc" (GONZALEZ, 2020, p. 50). Nesse sentido, é possível pensar Amefricanidade também como pedagogia negra. Uma categoria centrada na agência negra, que incorpora e emaranha múltiplas sabedorias, configurando processos formativos que conectam aprender-ensinar-criar, como fundamentos e práticas que organizam a vida e sustentam comunidades.

\section{Pedagogia negra: A CORPOREIDADE}

Festas, manifestações, música e dança são algumas expressões da corporeidade negra no cotidiano. Ela recupera os saberes inscritos nos corpos e, na comunhão destes, expressa sentidos de resistência e atos de rebeldia, pois "o corpo, naquelas comunidades, cumpre um papel imediato: realiza a ação direta da produção da presença" (TAVARES, 2012, p. 81). Os usos e traçados do corpo promovem e são 
promovidos por representações e ações políticas e, por isso, funcionam como dispositivos de agências múltiplas para a reivindicação, a luta e a conquista de direitos.

A corporeidade negra é laudatória da multiplicidade de maneiras de fazer consigo na relação com o outro, nas quais se disputa um futuro com direitos concomitante às reverências ao passado mítico, ao afirmar a presença da diferença na sociedade. Celebrações, festas, danças e músicas retiram os sujeitos do lugar imposto na ordem urbana (LEFEBVRE, 2004) ao exibir diferentes experiências sensíveis de cidade, sugerindo relações plurais afirmadoras e fundadoras das diferenças sociocultural e racial. Elas reconfiguram a teia de relações humanas, ao fazerem aparecer singularidades criativas que tencionam o modelo de cidade, as interações humanas e as formas de ser, expressando um plano de imanência em que as vidas e os mundos possíveis podem se anunciar.

Os corpos negros demonstram suas lutas pela conquista de direitos, à medida que põem em pauta o conflito entre o sujeito corporificado e o corpo-produto, resultante do capitalismo comercial e financeiro, pois suas presenças transformam o modo como a cidade é apropriada e simbolizada, subvertendo a ordem urbana. $E$, recorrendo a Ribeiro (2007, p. 4), podemos salientar que "o corpo, ao aglutinar impulsos vitais e normas sociais, constitui-se numa concreta demonstração da conquista ou da ausência de direitos. A sua autonomia, liberdade de movimento e plena realização informam sobre a afirmação do sujeito social."

As espacialidades e as vias de temporalidade do ritual se imbricam circularmente, informando um modo de viver, o social que não dissocia tempo e espaço e, por isso, interpela um modo de compreensão do mundo, no qual o corpo ganha centralidade. Com o corpo, aliás, percebemos, sentimos o mundo e, por intermédio dele, "desenvolvemos e aperfeiçoamos a comunicação com outras pessoas, com outros indivíduos, criando símbolos que nos permitem significar expressivamente a realidade" (TAVARES, 1997, p. 220).

O pertencimento a um grupo e o compartilhamento de valores, assim como modos de fazer consigo na relação com o outro, se expressam na corporeidade, considerando serem constituídas de ações que estilizam a existência e concorrem para a significação da realidade. Durante festas, danças, reuniões públicas e exibições nas redes sociais, os corpos salientam o compartilhamento de experiências e de práticas de si, confirmadoras de existências e posicionamentos políticos. No corpo, ressalta Tavares (1997, 2012), arquivam-se experiências cotidianas, comunicadas para o mundo, por meio dos gestos que são memórias corpóreas e, nas quais, o movimento é registrado como algo produzido e elaborado em contextos específicos.

A corporeidade não é só o local da memória do grupo, é como a memória e o movimento em direção ao novo se organizam. Ligiéro (2011) propõe o conceito de motrizes para pensar as performances do corpo negro, sendo aquele um conhecimento corporal resultante da interatividade entre cantar-batucar-dançar com a filosofia e a visão cósmica da tradição que garante sua continuidade. A proposição de motrizes culturais supõe uma memória corporal que registra as lutas e os desafios pelos quais o corpo negro, a fim de se constituir, passou. Uma recusa aos modos de ser/estar impostos pelo escravismo e colonialismo e, simultaneamente, uma potência de dialogar, com aspectos das culturas hegemônicas, apropriando-se de elementos e travestindo outros, 
com vistas a constituir o corpo e as performances afro-brasileiras. As motrizes, cumpre dizer,

\begin{abstract}
são e serão sempre ferramentas de transporte entre o mundo dos vivos e dos ancestres, entre o performer e a comunidade, entre o ser operário e o artista, entre o tempo do sacrifício cotidiano e o tempo das glórias e levezas míticas, não importa a época nem a sua localização geográfica (LIGIÉRO, 2011, p. 130).
\end{abstract}

O corpo negro, constituído como corporeidade participa das redes sociais, da ocupação do espaço público e cerimônias com o objetivo de comunicar a cultura e a história afro-brasileira por meio de danças, ritmos, músicas, mas também de narrativas e outras formas de sentir e perceber o mundo que integram outras maneiras de aprenderensinar-criar. Os eventos que reúnem corpos e tornam visíveis a corporeidade negra são momentos de composição de outras narrativas sobre si mesmos, pois, nestas ocasiões, apresentam processos criativos de formação de conhecimentos sociais, compartilhamento de saberes políticos e colaboração para melhor viver nos territórios onde habitam.

A corporeidade negra condensa situações de encontro e confronto que iluminam a diversidade de sujeitos, cujos desejos, expectativas e lutas convergem e divergem. Afinal, consideramos que há inúmeras corporeidade negras, tantas quantas são os modos de viver e habitar das populações negras. Funk, hip hop, pagode, samba, jongo, batuque, maracatu e inúmeras outras expressões artísticas, e modos de viver cotidianos são redes socioculturais e políticas que propõem a formação de sujeitos para reivindicar direitos e reconhecer os direitos de outros. Cada uma dessas corporeidades aponta processos educativos nos quais circulam direitos, criação, fruição estética e participação política nos quais a tríade "cantar-batucar-dançar" (LIGIÉRO, 2011), não é apenas um meio cultural, é a afirmação de uma diferença que reconhece na diferença de outros a possibilidade de construir um mundo em comum.

A corporeidade dos sujeitos se liberta pelo prazer e pela expressividade, ela é um texto a ser lido, cuja compreensão impõe o rompimento com a racionalidade dominante que o aprisiona na condição de receptáculo de pensamentos, suporte de indumentárias e reprodutor de gestos oriundos da consciência. Recorrendo a Oliveira (2005, p.101), podemos dizer que "é preciso ler o texto do corpo para vislumbrar nele a cosmovisão que dá sentido à história dos africanos e afrodescendentes espalhados no planeta".

Como destaca Sodré (1997), o corpo é, na tradição africana, um microcosmo onde se inter-relacionam experiências da materialidade do espaço, recortado por diferentes escalas (a casa, a rua, a cidade, a região). Ademais, complementa o autor, é a mística que o simboliza e o espaço mítico em que habitam os deuses. Por isso, apropriarse da cidade com o corpo é uma tomada de posse de si mesmo.

As apropriações das redes sociais e da cidade pela corporeidade negra são performances políticas (DAMASCENO, 2015). Ações planejadas e disputadas, reveladoras de situações de conflito e acordo nas quais diferentes sujeitos, podem se encontrar e se confrontar. Pensando no debate de Gomes (2017, p. 69), sobre os saberes produzidos 
pela comunidade negra e sistematizados pelo movimento negro estamos nos referindo à saberes "identitários, políticos e estéticos corpóreos". Com intensidades distintas, cada um deles se expressa na presença e nas relações que os sujeitos negros constroem no cotidiano.

As corporeidades possuem um fluxo marcadamente político, por realizarem apropriações materiais e imateriais de lugares, mídias, meios e mensagens que permitem ser e criar múltiplas existências. As iniciativas que tornam a corporeidade negra presentes publicamente fazem das redes sociais e das praças públicas um campo de disputas, entre diferentes compreensões de viver e formas de apropriação sensível do mundo. Pois, as corporeidades são meios de comunicar construções sociopolíticas, sendo experiências de criação de possibilidades que, nas palavras de Santos (2020, p. 104), ao interpretar o pensar-viver dos grupos periféricos, especialmente na figura do malandro, significam "produzir poéticas corporais, corporeidades, que se transformam e se transformarão, a cada dia, em armas de resistência contra o racismo e contra práticas políticas de subalternização".

As corporeidades negras na web ou nas ruas das cidades criam locais de convivência e debate sobre a vida, nos quais os múltiplos outros podem participar e questionar. O corpo é um elemento básico da existência humana e na perspectiva afrobrasileira, um microcosmo do universo ao funcionar como o solo de símbolos das estruturas que regem a sociedade e das transformações possíveis. Ele é a menor unidade/espacialidade da vida, é com e através dele que ações, relações e interações ocorrem. Portanto, "não é simplesmente fonte de todo movimento e ação", mas "um acontecimento que inaugura a existência" (OLIVEIRA, 2005, p. 128).

\section{CONSIDERAÇÕES FINAIS}

pedagogias negras reivindicam mais que o direito ao conhecimento, à inserção das histórias, memórias e modos de fazer das populações negras. Elas reivindicam a diferença e a pluralidade, como ser e modo de ensinar e aprender. O reconhecimento de sua competência criativa e dos processos organizados para colaborar e compartilhar saberes e práticas. Numa primeira mirada, os movimentos de pessoas negras se expressam na garantia de direitos previstos na constituição, com vistas a assegurar condições de igualdade para a reprodução e a manutenção da vida. Mas vão além, ao buscar o direito à diferença, como direito fundamental para reconhecer o aprenderensinar-criar próprios das populações negras como parte fundamental de seus modos de vida e de suas organizações sociais, políticas, culturais e religiosas, muitas vezes, transpondo a barreira que separa instituições e movimentos em nichos de atuação.

$\mathrm{O}$ direito à diferença se constitui num movimento necessário por colocar o debate não só no nível do reconhecimento de heranças e conhecimentos, mas na esfera da criação de conteúdos, metodologias e práticas, considerando as relações de saberpoder que os atravessam.

O direito à diferença, reconhecimento das múltiplas expressões ético-estéticas fundadas no corpo, expressão de saberes e fazeres, modos de organização sócio-territorial e apropriação da natureza. Inclui ainda o debate sobre as relações de poder-saber fundantes do 
patrimônio oficializado institucionalmente e a representatividade da diversidade (SANTOS et al., 2021, no prelo).

Compreendido desta forma, o direito à diferença abarca as experiências e ações das comunidades negras brasileiras as quais, no campo da educação, tencionam os ordenamentos, normas e metodologias para elaborar processos formativos mais emancipatórios e, simultaneamente, buscam reconhecer a diversidade ontológica e epistemológica das populações negras em suas diferentes formas de organização e expressões sócio-territoriais.

As pedagogias negras ao construírem o direito à diferença, enquanto direito fundamental e inalienável, apontam que o aprender-ensinar-criar emerge do cotidiano das populações negras diaspóricas na criação de vidas mais vivíveis, nas condições materiais e simbólicas impostas pela sociedade desigual, discriminatória e racista. Por isso, são invenções de trajetórias, narrativas e práticas que se contrapõem aos discursos dominantes. Elas se insurgem ao problematizar os modos de organização, distribuições e posicionamentos discricionários determinados por conceitos, quando criados pelas instituições de ensino e pesquisa; valores e ética, quando integram os princípios morais de uma sociedade e a conduta dos indivíduos, e imaginário, ao definir modos de pensar e sentir.

Das inúmeras expressões das pedagogias negras, elegemos três para apresentar os modos pelos quais problematizam o aprender-ensinar-criar e abrem possibilidades para novos processos educacionais ao questionar as pedagogias ocidentais, mas sobretudo problematizar as próprias práticas e saberes ao buscar reconhecer os múltiplos outros que participam de seus conhecimentos, se movendo na direção do direito à diferença.

Artigo recebido em: 01/04/2021

Aprovado para publicação em: 26/10/2021

\section{BLACK PEDAGOGIES: ANTI-RACISM, GOOD LIVING AND CORPOREALITY}

ABSTRACT: Black Pedagogies comprise ways of doing, thinking and being able to transform and question knowledge and practices already established in Western pedagogies. It also problematizes the proposals generated within the scope of Black teaching and learning practices. In an effort to understand, we discuss anti-racism, Black women's thinking and corporeality in the light of three methodological strategies - multiplicity, complexity and interdependence, revealing understandings about the learning-teaching-creating processes that shape black pedagogies. Finally, we consider that these pedagogies mobilize the struggle for rights in its various dimensions, especially the right to difference, as a fundamental and inalienable right.

KEYWORDS: Black Pedagogies. Anti-racism. Black Women. Corporeality. 
SOTERO, E. C.; PEREIRA, I. D.; SANTOS, S. B. dos.

PEDAGOGÍAS NEGRAS: ANTIRRACISMO, BUENA VIDA Y CORPORALIDAD

RESUMEN: Las Pedagogías Negras comprenden formas de hacer, pensar y poder transformar y cuestionar conocimientos y prácticas ya establecidos en las pedagogías occidentales. También problematizan las propias propuestas creadas en el contexto de las prácticas de enseñanza y aprendizaje de los negros. En un esfuerzo por comprender, discutimos el antirracismo, el pensamiento de las mujeres negras y la corporalidad a la luz de tres estrategias metodológicas: multiplicidad, complejidad e interdependencia, que revelan compresiones en los procesos de aprendizaje-enseñanza-creación que dan forma a las pedagogías negras. Finalmente, consideramos que estas pedagogías movilizan la lucha por los derechos en sus diversas dimensiones, especialmente el derecho a la diferencia, como derecho fundamental e inalienable.

PALABRAS CLAVE: Pedagogías Negras. Antirracismo. Mujeres Negras. Corporalidad.

\section{REFERÊNCIAS BIBLIOGRÁFICAS}

ACOSTA, A. O Bem Viver: uma oportunidade para imaginar outros mundos. Tradução de Tadeu Breda. São Paulo: Autonomia Literária/Elefante, 2016.

ALMEIDA, S. O que é racismo estrutural. Belo Horizonte: Letramento, 2018.

BRASIL, 2004. Diretrizes Curriculares Nacionais para a Educação das Relações ÉtnicoRaciais e para o Ensino de História e Cultura Afro-Brasileira e Africana. RESOLUÇÃO No. 1, de 17 de junho de 2004 do Conselho Nacional de Educação/Conselho Pleno/ DF. Brasília, DF, outubro, 2004.

CEPESC; SPM. Gênero e diversidade na escola: formação de professoras/es em Gênero, Orientação Sexual e Relações Étnico-Raciais. Livro de conteúdo. Versão 2009. - Rio de Janeiro: CEPESC; Brasília: SPM, 2009.

GOMES, N. L. O movimento negro educador: saberes construídos nas lutas por emancipação. Petrópolis: Vozes, 2017.

GOMES, N. L; SILVA, P. B. G. O Desafio da Diversidade In: Experiências étnico-cultural para a formação de professores. 3. ed. Belo Horizonte: Autêntica editora, 2011. p. 1126.

GONZALEZ, C. Z. Mulheres Negras em Movimento: Ativismo transnacional na América Latina. Tese (Doutorado em Sociologia). Universidade de São Paulo, São Paulo, 2017.

GONZALEZ, L. "Racismo e sexismo na cultura brasileira". In: SILVA, L. A. et al. Movimentos sociais urbanos, minorias e outros estudos. Ciências Sociais Hoje, Brasília, ANPOCS n. 2, p. 223-244, 1983.

Inter-Ação, Goiânia, v.46, n.3, p. 1314-1329, set./dez. 2021. Disponível em: <http://dx.doi.org/10.5216/ia.v46i3.70669>. 
GONZALEZ, L. "A categoria político-cultural de amefricanidade”. Tempo Brasileiro, Rio de Janeiro, n. 92/93, p. 69-82, jan./jun. 1988a.

GONZALEZ, L. "Por um feminismo afrolatinoamericano". Revista Isis Internacional, Santiago, v. 9, p. 133-141, 1988b.

GONZALEZ, L. Por um feminismo afro-latino-americano: ensaios, intervenções e diálogos. Rio de Janeiro: Zahar, 2020.

HOOKS, B. Ensinando a transgredir: a educação como prática da liberdade. São Paulo: Ed. WMF Martins Fontes, 2013

KENDI, I. X., 2020. Como ser antirracista; traduzido por Edite Siegert. Rio de Janeiro: Alta Books, 2020.

LÉFÈBVRE, H. A Revolução Urbana. Belo Horizonte: EDUFMG, 2004.

OLIVEIRA, L. F. de. Educação e militância descolonial. Rio de Janeiro: Editora Selo Novo, 2018.

LIGIÉRO, Z. Corpo a Corpo: estudo das performances brasileiras. Rio de Janeiro: Garamond, 2011.

OLIVEIRA, E. D. de. Filosofia da ancestralidade: corpo e mito na filosofia da Educação Brasileira. 2005. Tese (Doutorado) - Universidade Federal do Ceará, Programa de Pósgraduação em Educação Brasileira, Fortaleza (CE), 2005.

OLIVEIRA, L. B. de. Corpos indisciplinados: ação cultural em tempos de biopolítica. São Paulo: Beca Produções, 2007.

PRESTES, C. R. S. Estratégias de promoção da saúde de mulheres negras: interseccionalidade e bem viver. 2018. 206 f. Tese (Doutorado em Ciências - Psicologia Social) - Instituto de Psicologia, Universidade de São Paulo, São Paulo, 2018.

RIBEIRO, A. C. T.. Corpo e imagem: alguns enredamentos urbanos, p. 105-117. Cadernos PPG-AU/FAUFBA/Universidade Federal da Bahia. Salvador, Faculdade de Arquitetura e Urbanismo, Ano 5, no especial, (2007) - Ana Clara Torres Ribeiro (Org.). Salvador: PPGAU/FAUFBA, 2007.

RIOS, F. A cidadania imaginada pelas mulheres afro-brasileiras: da ditadura militar à democracia. BLAY, Eva; AVELAR, Lucia (ORGs). In: 50 anos de feminismo: Argentina, Brasil e Chile. São Paulo. Edusp, 2017. 
SOTERO, E. C.; PEREIRA, I. D.; SANTOS, S. B. dos.

RODRIGUES, C.; Prado, M. A. M. “Movimento de mulheres negras: trajetória política, práticas mobilizatórias e articulações com o estado brasileiro". Psicol. Soc. v. 22 n. 3 Florianópolis, 2010.

SANTOS, L. P. A filosofia do malandro: estéticas de um corpo encantado pela desobediência. Revista da ABPN, [S.I.], v. 12, n. 31, dez. 2019 - fev. 2020, p. 95-112.

SILVA, G. C.; PETIT, S. H. Uma experiência de formação de professor@s de áreas quilombolas por meio da pret@gogia. Muitas Vozes, Ponta Grossa, v. 3, p. 243-261, 2014.

SILVA, P. B. G.; SILVÉRIO, V. R. Educação e ações afirmativas: entre a injustiça simbólica e a injustiça econômica/ organização, Petronilha Beatriz Gonçalves e Silva e Valter Roberto Silvério. - Brasília: Instituto Nacional de estudos e Pesquisas Educacionais Anísio Teixeira, 2003. 270 p.

SODRÉ, M. Corporalidade e liturgia negra. Revista do Patrimônio Histórico e Artistíco Nacional. Negro Brasileiro. Brasília, IPHAN. n. 25, p. 29-34, 1997.

TAVARES, J. C. Dança de guerra - arquivo e arma: elementos para uma teoria da capoeiragem e da comunicação corporal afro-brasileira. Belo Horizonte: Nandyala, 2012.

TAVARES, J. C. Educação Através do Corpo: a representação do corpo nas populações Afro- Americanas. Revista do Património Histórico e Artistíco Nacional. Negro Brasileiro, Brasília, IPHAN. n. 25, p. 216-221, 1997.

WERNECK, J.; IRACI, N.; CRUZ, S. (org.). Marcha das mulheres negras. Fundação Ford, [S.I.], 2015.

Edilza Correia Sotero: Possui graduação em Ciências Sociais pela Universidade Federal da Bahia (2006), mestrado em Sociologia pela Universidade de São Paulo (2010) e doutorado em Sociologia pela Universidade de São Paulo (2015). Realizou PósDoutorado na Brown University (2015-2016). Atualmente é Professora Adjunta no Departamento de Educação I da Universidade Federal da Bahia.

Orcid: https://orcid.org/0000-0002-9945-2597

E-mail: edilzacsotero@smail.com

Ilaina Damasceno Pereira: Doutora em Geografia pela Universidade Federal Fluminense (UFF). Mestre em Geografia pela Universidade Federal doo Ceará (UFC). Licenciada e bacharel em Geografia pela Universidade do Estado do Ceará (UECE). Atualmente, é professora adjunta do Departamento de Estudos Aplicados ao Ensino da Faculdade de Educação da Universidade do Estado do Rio de Janeiro (UERJ), Campus Maracanã.

Orcid: https://orcid.org/0000-0002-5924-7329

E-mail: ilaina.damasceno@gmail.com

Inter-Ação, Goiânia, v.46, n.3, p. 1314-1329, set./dez. 2021. Disponível em: <http://dx.doi.org/10.5216/ia.v46i3.70669>. 
Sônia Beatriz dos Santos: Possui Pós-doutorado em Raça, Gênero e Política Pública, pelo Hubert H. Humphrey Institute of Public Affairs, University of Minnesota (20082009). É Ph.D. em Antropologia Social pela University of Texas at Austin (2008) com especialização em Diáspora Africana; e mestre em Sociologia com concentração em Antropologia pela Universidade Federal do Rio de Janeiro (2000). É Professora Adjunta da Faculdade de Educação, Departamento de Ciências Sociais e Educação, da Universidade do Estado do Rio de Janeiro (UERJ).

Orcid: https://orcid.org/0000-0002-4354-5954

E-mail: soniabsantos@yahoo.com

Este periódico utiliza a licença Creative Commons Attribution 3.0, para periódicos de acesso aberto (Open Archives Initiative - OAI). 